\title{
Theoretical and experimental investigation of the thermal behaviour of a two-speed dual clutch transmission
}

\author{
Xingxing Zhou \\ University of Technology Sydney, \\ 15 Broadway, Ultimo, NSW2007, Australia \\ and
}

Guangdong Academy of Agricultural Sciences

Email: Zhouxingxing0808@163.com

\author{
Jiageng Ruan* \\ University of Technology Sydney, \\ 15 Broadway, Ultimo, NSW2007, Australia \\ Email: Jiageng.Ruan@uts.edu.au \\ ${ }^{*}$ Corresponding author
}

\section{Bo Zhu}

HeFei University of Technology

193 Tunxi Rd, Baohe Qu,

Hefei Shi, Anhui Sheng, 230000, China

Email: zhubo@hfut.edu.cn

\author{
Nong Zhang \\ University of Technology Sydney, \\ 15 Broadway, Ultimo, NSW2007, Australia \\ Email: Nong.Zhang@uts.edu.au
}

\begin{abstract}
Understanding the heating behaviour of automotive transmissions in an important step in prototype development, it plays a significant role in achieving appropriate tolerances at the design phase and strongly influences the system's durability in the long term. Furthermore, lubricant viscosity is strongly dependent on operating temperature, understanding this behaviour will provide insight into how transmission efficiency is affected during vehicle warm-up. In this paper, an experimental and simulation based study has been conducted to investigate the thermal behaviour of a two-speed dual clutch transmission (DCT) that has been developed for electric vehicle applications. This is achieved through the modelling of the power losses in the system that is then integrated with a compact thermal model of the transmission. Transient heating simulations for the transmission are conducted at constant speeds and compared with experimental studies, showing a strong correlation between results. Simulations are then utilised to investigate the load and speed dependencies of the transmission's thermal behaviour.
\end{abstract}


Keywords: thermal behaviour; heat dissipation; power losses; DCT; dual clutch transmission.

Reference to this paper should be made as follows: Zhou, X., Ruan, J., Zhu, B. and Zhang, N. (2018) 'Theoretical and experimental investigation of the thermal behaviour of a two-speed dual clutch transmission', Int. J. Vehicle Performance, Vol. 4, No. 3, pp.237-258.

Biographical notes: Xingxing Zhou received his $\mathrm{PhD}$ in 2014 from the University of Technology Sydney. His research interests include the analysis of transmission dynamics, transmission thermal behaviour and transmission shifting control.

Jiageng Ruan received his BS in Mechanical Engineering in 2010 from HuNan University. In 2014, he received his Doctoral degree in Engineering from the University of Technology Sydney. His research interests include the development of novel power splitting transmissions for hybrid electric vehicles, multi-speed transmission dynamics and control.

Bo Zhu is currently a Senior Research Associate at HeFei University of Technology, China. He received his PhD from the University of Technology, Sydney in 2015. He has been working in automotive manufactures for 10 years, including WanXiang Electric Vehicle Co. Ltd., Hangzhou China; and BAIC Motor Electric Vehicle Co. Ltd., Beijing, China. His current research interests include electric vehicle modelling and simulation, vehicle performance analysis and control, power-train analysis for hybrid and electric vehicles, and the dynamics and control of the dual clutch transmission power-trains system.

Nong Zhang received his BE in 1982 from Northeastern University, ME in 1984 from Shanghai Jiao Tong University, China, and PhD in 1989 from the University of Tokyo, Japan. He worked at several universities in China, Japan, USA and Australia, respectively before joining the Faculty of Engineering of the University in 1995. Since 2009, he has been Professor of Mechanical Engineering, at School of Electrical, Mechanical and Mechatronic Systems. For more than 20 years, he has been involved in research in areas of dynamics and control of automotive systems including powertrains with various types of transmissions, hybrid propulsion systems, vehicle dynamics, passive and active suspensions, and mechanical vibration including experimental modal analysis, rotor dynamics, cold rolling mill chatter and machine condition monitoring.

\section{Introduction}

In recent years, there has been considerable effort devoted to producing energy efficient vehicles and machines, not only for economic reasons, but also to contribute to meet the requirement for emissions reduction. Improvement of the fuel consumption of existing technologies and reduction of greenhouse gas emissions are some of the most important reasons for developing new vehicle technologies. Generally, in conventional combustion vehicles, one-third of the fuel energy is used to overcome friction in the powertrain system, including the engine, transmission, tyres and brakes. By making the best use of new technologies for friction or wear reduction in vehicles, friction losses can be cut down by $18 \%$ in the short term (5-10 years) and by $61 \%$ in the long term (15-25 years). Furthermore, the energy losses related to friction in a pure electric vehicle (EV) are 
estimated to be only half those of a conventional combustion vehicle (Holmberg et al., 2012). As a consequence, the development of commercially viable hybrid electric vehicles (HEVs), fuel cell vehicles (FCVs) for using in the short to mid-term, and pure EVs in the long term represent the automotive industry's major initiatives towards solving these related issues (Chan et al., 2010).

Pure EVs currently being available on the market are equipped with fixed reduction transmissions (i.e., one reduction gear), trading between the vehicle performance characteristics of acceleration and grade climbing against vehicle top speed, whilst maximising driving range (i.e., driving efficiency). More research and development is now focused on the deployment of multi-speed transmissions in place of fixed reduction gears, as these are expected to improve the EV performance without degrading the overall driving range. As has been discussed in our previous work (Roser et al., 2013; Walker et al., 2013; Zhou et al., 2013a, 2013b), the use of these multi-speed transmissions in EVs can improve the average operating efficiency of the motor and therefore range, it is even possible to reduce the size of the electric motor. Examples of the application of two-speed transmissions include the deployment in the front wheel drive of the BMW i8 (Merwerth, 2014), applications to novel four-wheel drive powertrains (Chen et al., 2013) and even applications in electric buses (Yang et al., 2014).

Computer aided engineering has enabled the rapid reduction in design and development times across all forms of engineering, reducing the requirements for prototyping and testing through the generation of reasonably accurate simulated data earlier in the design life. Lechner (Naunheimer et al., 2011) indicates that the thermal behaviour of automotive transmissions is not considered early in the design life due to its inherent complexity. However as indicated in Naunheimer et al. (2011) among, the thermal expansion of transmission cases, for example, can change gear axes geometry positions, gears clearances, and lubricant regime and film conditions, and consequently, dissipated heat during normal operation. Furthermore, it is of great importance to know the temperature of oil lubricated transmission systems, and the quantity of required oil cooling. The prediction of the thermal behaviour of a transmission is beneficial to the evaluation of cooling and lubrication conditions, and can aid in the analysis of transmission efficiency. Therefore, understanding the thermal behaviour of automotive transmissions is essential for a number of design considerations, notably cooling system design, operational behaviour and reliability. Consequently, significant benefits can be attained through the development of models to predict the thermal behaviour earlier in the design life.

Transmission thermal behaviour is directly affected by the heat generated from transmission power losses. Hence, it is important to study the sources of power losses in a transmission as part of the model development. The total power losses within a gear-train for any transmission are generally made up from several sources, including gear friction (Heingartner and Mba, 2003; Diab et al., 2006; Xu et al., 2007; Li et al., 2009), windage (Diab, 2004; Dawson, 2006; Eastwick and Johnson, 2008) and oil churning (Changenet et al., 2005; Changenet and Velex, 2007). Other important drag torque sources have to be considered as well e.g., bearings and seals (Harris, 1966; Hashimoto et al., 1984; Changenet et al., 2005), synchroniser and free-pinion losses (British Standards Institute, 2001; Walker et al., 2011). There are only a few reported works on the 
entire transmission power losses (Iritani et al., 1999; Michlin and Myunster, 2002; Rosander et al., 2008; Seetharaman, 2008; Patel and Patel, 2012), which mostly focus on the manual transmission (MT) gearbox, these, therefore, do not include wet clutch losses in the transmission models.

Some works (Joule et al., 1988; Coe, 1989; Changenet et al., 1996; Phillips and Association, 1996; Handschuh and Kilmain, 2002) have performed thermal analysis of manual and automatic transmissions, but there is limited published work that combines gearbox components and wet clutch losses, an example being (Marklund et al., 2007) where limited slip differentials are studied. In particular, there is no published report on the study of thermal behaviour within a wet dual clutch transmission (DCT). If the clutch is immersed in oil, torsional resistance and its influences caused by the viscous shear between wet clutch plates should be considered as well (Kato and Murasugi, 1993; Iqbal et al., 2011), as these will significantly influence the power losses and heat generated in the transmission, with direct implications for vehicle warm up and heat rejection needs for the transmission.

The purpose of this paper is to develop a compact thermal model of a DCT that integrates the power losses developed and relates these to the heating behaviour of the transmission. Such models have specific applications early in the design lifecycle as they allow prediction of the thermal behaviour, with direct impact on transmission durability and reliability. Where designing to accommodate thermal effects will directly impact on tolerance requirements for critical components (i.e., bearing or shaft alignment), which will significantly influence the system durability and reliability. Furthermore (Chiara and Canova, 2013) identifies the reduction in lubricant viscosity through improved thermal management as an important avenue for improving transmission efficiency. Specific applications of this model could also include simulating the cold start behaviour of simulated vehicles in driving cycle based studies for evaluation of fuel economy, etc.

Given the analysis of drag torque of DCT (Changenet et al., 1996) and simulation existing result thermal behaviour (Coe, 1989), a comprehensive study of the power losses and resulting thermal behaviour of a wet DCT is evaluated in this paper, then, validated in the testing bench. Given the layout of the DCT under investigation, that contributions to power losses in the transmission include wet clutches, concentric shaft viscous shear, as well as gear and bearing power losses (i.e., gear meshing, gear windage, churning, bearing losses and oil seal losses). Utilising the developed drag torque model as the heat source a thermal model of the system is developed and simulations with experimental verification are performed to demonstrate the effectiveness of the model. This paper is organised as follows. In Section 2, after briefly discussing the different source of power losses in the DCT, the thermal behaviour model will be introduced and modelled. Then, the experimental aspects comprising of the description of the University of Technology Sydney (UTS) test rig, and the power loss and thermal rise test procedures are presented and discussed in Section 3. In Section 4, results from three aspects will be presented. These include the experimental test results, simulation results from implemented drag torque model and the thermal behaviour model and comparison of said models. Finally, major conclusions are drawn from the study, these are summarised in Section 5 . 


\section{Theoretical analysis of power losses and heat dissipation in a two-speed dual clutch transmission}

The system under consideration is modified from a 6-speed DCT (DQ250) into a twospeed DCT as shown in Figure 1. The two-speed DCT housing is made from an aluminium alloy. The DCT used in this testing comprises of dual wet clutches with a single drum providing input power from the electric motor. The concentrically aligned output shafts are connected to the inner clutch (C1) and the outer clutch (C2). Each output shaft is connected to either the 1st or the 2nd gear. C1, shown in green, connects the outer input shaft with the 1st gear, and $\mathrm{C} 2$, shown in red, connects the inner input shaft with the 2nd gear. In order to make the transmission control system simpler and reduce manufacturing costs, there are no synchronisers in this DCT. Shifting is achieved through the simultaneous opening and closing of both clutches to achieve power on gear shifts. For this special layout, a vehicle equipped with a DCT not only changes speed smoothly with nearly no power hole, as identified by Goetz et al. (2004), but it also improves the EV efficiency.

There are several major differences between the EV powertrain and that of a conventional vehicle. These make the powertrain simpler and influence the rate of heat generation in the transmission. These are:

- The EV power train is launched from a stationary state using motor torque only, therefore no heat is generated in the friction clutch, this significantly reduces the thermal load. A conventional DCT will use friction clutches to launch the vehicle thereby generating considerable friction energy that must be dissipated, frequently using small heat exchangers.

- No synchronisers are used in the powertrain to isolate the open wet clutch from the gear-train, consequently, wet clutch drag will always contribute to powertrain losses.

- The wider operating region of an electric motor requires fewer gear pairs in the transmission, in this case only two gears are used in the DCT. Therefore, there are significantly fewer gear changes in the transmission (Walker et al., 2013), reducing the rate of heat generation in comparison to a conventional vehicle.

\subsection{Power losses analysis}

The sources of power loss in a two-speed DCT (Figure 2), or drag torque, can be divided into five major origins: gears related meshing, windage and churning losses, bearings and oil seal related losses, concentric shaft related viscous shear loss, and disengaged wet clutch caused drag torque losses, as shown in equation (1). For each individual power loss source, the following formulae have been implemented in the simulation code.

$$
P_{L}=P_{C o n}+\sum P_{B}+\sum P_{G}+P_{C h}+P_{C l},
$$

where $P_{L}$ is total power losses in DCT, $P_{\text {Con }}$ is power losses caused by concentric shaft drag torque, $P_{B}$ is power losses caused by bearings drag torque, $P_{G}$ is power losses caused by gear meshing drag torque, $P_{C h}$ is power losses caused by gear churning, $P_{C l}$ is power losses caused by wet clutch plates drag torque. Figure 2 shows the energy losses flow from the electric machine to the environment through heat dissipation. 
Figure 1 Schematic of a two-speed DCT powertrain system (see online version for colours)

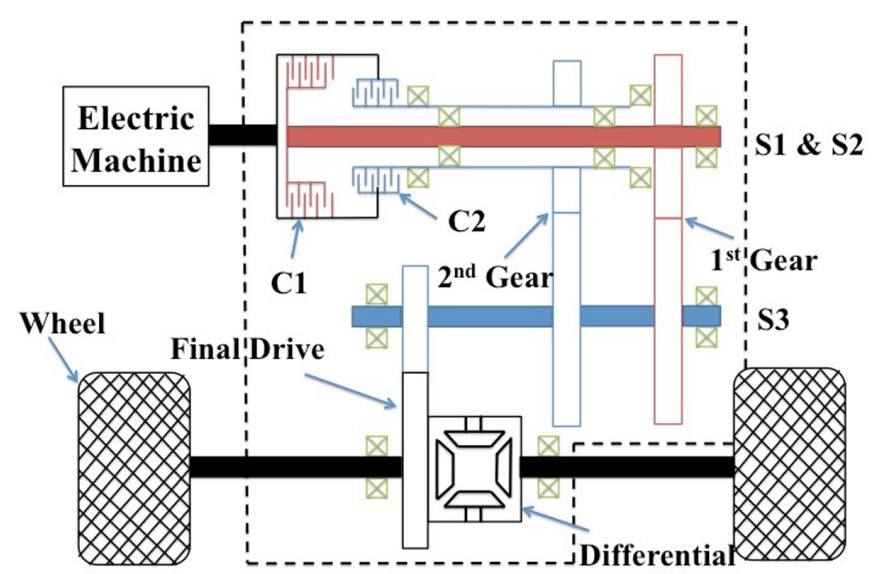

Figure 2 Energies flow chart for the two-speed DCT

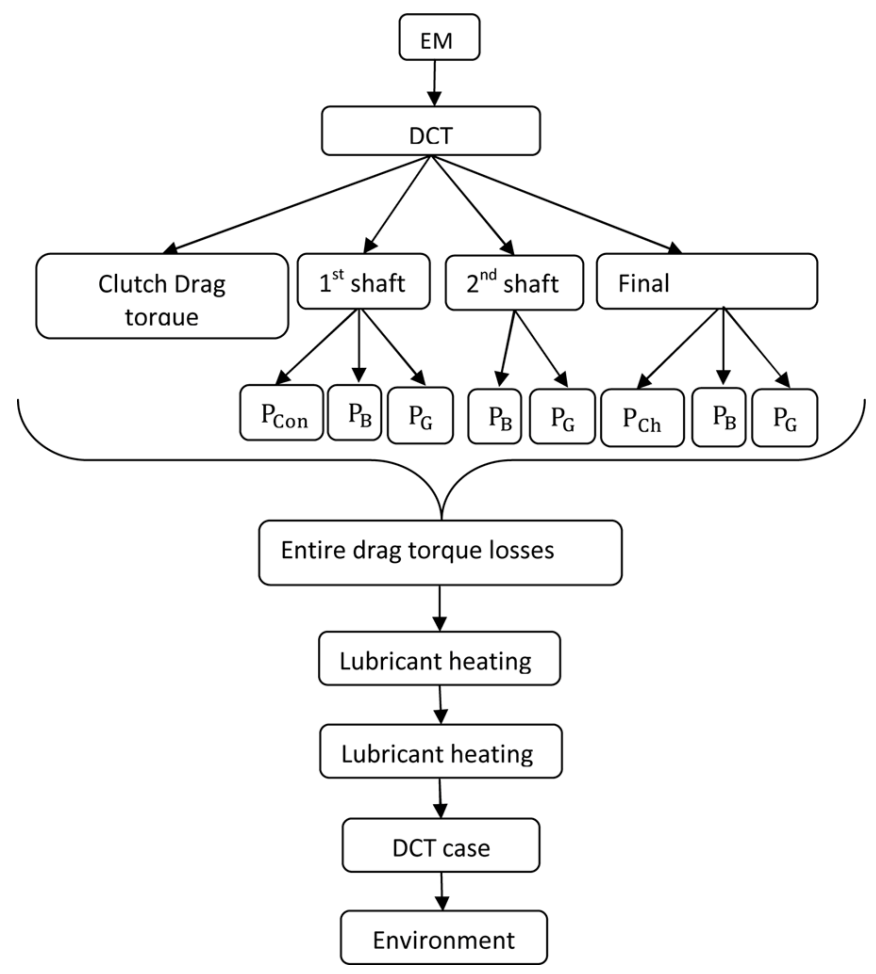

If engaged with 1 st gear, clutch 1 is closed, while clutch 2 will be open and subsequently develop a drag torque.

$$
\begin{aligned}
& \left(T_{m}-T_{\text {con }}-T_{B(1,2)}\right) r_{1 s t}=T_{1 \text { st_output_outer }} \\
& {\left[T_{1 \text { st_output_outer }}-T_{\mathrm{GM}_{1 \mathrm{st} \_ \text {pair }}}-T_{B(6,7)}-\left(T_{G M_{2 \text { nd_pair }}}+T_{C l_{C 2}}+T_{B(3,4,5)}\right) r_{2 \text { nd }}\right]=\frac{T_{2 \text { nd_output }}}{r_{3 \text { rd }}}}
\end{aligned}
$$




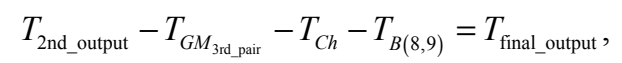

where $T_{m}$ is motor output torque; $T_{\text {con }}$ is drag torque caused by concentric shafts viscous shear resistance; $T_{B}$ is drag torque caused by bearings; and $r$ is gear ratio, $T_{1 \text { st_output outer }}$ represents the output torque of the outer concentric shaft. $T_{\mathrm{GM}}$ is drag torque caused by gear pairs meshing, $T_{C l}$ is the drag torque caused by wet clutch packs. $T_{c h}$ is the drag torque caused by churning. And the individual power losses can be calculated in rotational speed multiplied by drag torque:

$$
P=T \omega .
$$

For the power losses caused by concentric shaft raised shear resistance is:

$$
P_{\text {Con }}=T_{\text {con }} \omega_{\text {motor }} \text {. }
$$

The total power loss caused by bearings and gear friction are:

$$
\begin{aligned}
& \sum P_{B}=\left(T_{B(1,2)} \omega_{\text {motor }}+T_{B(3,4,5)} \omega_{\text {motor }} \frac{r_{2 \text { nd }}}{r_{1 \mathrm{st}}}+T_{B(6,7)} \frac{\omega_{\text {motor }}}{r_{1 \mathrm{st}}}+T_{B(8,9)} \frac{\omega_{\text {motor }}}{r_{1 \mathrm{st}} \times r_{3 \mathrm{rd}}}\right) \\
& \sum P_{G}=\left(T_{G M_{\text {1st pair }}} \frac{\omega_{\text {motor }}}{r_{\text {1st }}}+T_{G M_{\text {2nd pair }}} \omega_{\text {motor }} \frac{r_{\text {2nd }}}{r_{\text {1st }}}+T_{G M_{\text {3rd pair }}} \frac{\omega_{\text {motor }}}{r_{1 \mathrm{st}} \times r_{3 \mathrm{rd}}}\right) .
\end{aligned}
$$

The power losses resulting from gear windage and churning is:

$$
P_{C h}=\frac{T_{C h} \omega_{\mathrm{motor}}}{r_{1 s t} \times r_{3 \mathrm{rd}}}
$$

The overall power loss caused by the clutch package is:

$$
P_{C l}=\frac{T_{C l_{C 2}} \omega_{\text {motor }} r_{2 \mathrm{nd}}}{r_{1 \mathrm{st}}} .
$$

Similarly, if engaged with 2nd gear, clutch 2 is closed, while clutch 1 open.

$$
\begin{aligned}
& \left(T_{m}-T_{\text {con }}-T_{B(3,4,5)}\right) r_{1 \mathrm{st}}=T_{1 \text { st_output_inner }} \\
& {\left[T_{1 \text { st_output_inner }}-T_{G M_{2 \text { nd _pair }}}-T_{B(6,7)}-\left(T_{G M_{\text {1st_pair }}}+T_{C l_{C 1}}+T_{B(1,2)}\right) r_{1 \text { st }}\right]=\frac{T_{2 \text { nd_output }}}{r_{3 \text { rd }}}} \\
& T_{2 \text { nd_output }}-T_{G M_{3 r d p a i r}}-T_{C h}-T_{B(8,9)}=T_{\text {final_output }} \\
& P_{\text {Con }}=T_{\text {con }} \omega_{\text {motor }} \\
& \sum P_{B}=\left(T_{B(1,2)} \frac{\omega_{\text {motor }} r_{\text {st }}}{r_{2 \mathrm{nd}}}+T_{B(3,4,5)} \omega_{\text {motor }}+T_{B(6,7)} \frac{\omega_{\text {motor }}}{r_{2 \text { nd }}}+T_{B(8,9)} \frac{\omega_{\text {motor }}}{r_{2 \mathrm{nd}} \times r_{3 \mathrm{rd}}}\right) \\
& \sum P_{G}=\left(T_{G M_{\text {1st pair }}} \omega_{\text {motor }} \frac{r_{\text {1st }}}{r_{\text {2nd }}}+T_{G M_{\text {2nd _pair }}} \frac{\omega_{\text {motor }}}{r_{\text {2nd }}}+T_{G M_{\text {3rd_pair }}} \frac{\omega_{\text {motor }}}{r_{\text {2nd }} \times r_{\text {3rd }}}\right)
\end{aligned}
$$




$$
\begin{aligned}
P_{C h} & =\frac{T_{C h} \omega_{\text {motor }}}{r_{2 \text { nd }} \times r_{3 \mathrm{rd}}} \\
P_{C l} & =\frac{T_{C l_{C 2}} \omega_{\text {motor }} r_{1 \mathrm{st}}}{r_{2 \mathrm{nd}}} .
\end{aligned}
$$

The overall efficiency of a DCT or any transmission, in general, can be obtained by monitoring the input and output speed and torque respectively.

$$
\frac{\omega_{\text {final }} T_{\text {final_output }}}{\omega_{\text {motor }} T_{\text {motor }}} \times 100 \%=E_{\mathrm{DCT}} .
$$

Further detail equations regarding calculation of components' drag torques and power losses can be referred from our previous work (Zhou et al., 2014), where both numerical and experimental investigation are conducted to study the entire two-speed DCT's drag torque. It was demonstrated that the proposed model performs well in the prediction of drag torque for the DCT, with an acceptable correlation between simulated and experimental results. Particularly, it was shown that the entire drag torque for the transmission is dominated by the viscous shear in the wet clutch pack and gear churning losses. Accordingly, the model can be applied to calculate the power losses the transmission.

\subsection{Heat dissipation}

The BS/ISO (British Standards Institute, 2001) model is adopted in this paper for the simulation of heat exchange through the transmission (British Standards Institute, 2001). The Remainder of this section was initially presented in our previous work (Zhou et al., 2013a, 2013b).

The quantity of heat, $Q_{C a}$, dissipated through the DCT case by convection can be calculated by:

$$
Q_{C a}=\int k A_{c a}\left(T_{\text {oil }}-T_{e n}\right) \mathrm{d} t,
$$

where, $k$ represents the heat transmission coefficient, which includes the internal heat transfer between oil and case, and the heat conduction through the case wall and the external heat transfer to the environment, usually surrounding air. $T_{\text {oil }}$ and $T_{\text {en }}$ mean the oil temperature and environment temperature, respectively with the unit of Kelvin.

$$
\frac{1}{k}=\frac{1}{\alpha_{\text {oil }}} \frac{A_{c a}}{A_{\text {oil }}}+\frac{\delta_{\text {wall }}}{\lambda_{\text {wall }}} \frac{A_{c a}}{A_{\text {oil }}}+\frac{1}{\alpha_{c a}} .
$$

The heat dissipation via the DCT case is determined by the larger value air-side, i.e., external side, thermal resistance at the case surface. The front two terms in the above equation can then be ignored. For high air velocities and thus good external heat transfer, it will be necessary to also consider the oil-side heat transfer. According to (British Standards Institute, 2001) an oil-side heat transfer coefficient of $\alpha_{\text {oil }}=200 \mathrm{~W} / \mathrm{m}^{2} \mathrm{~K}$ is assumed. But it requires investigation and revision for different oil types. The heat conduction through the transmission case should only be considered in special cases, 
such as in the case of double-walled cases, cases with insulation and non-metallic cases. And the appropriate coefficient of thermal conduction, $\lambda_{\text {wall }}$, has to be expressed in the case material in question.

The air-side heat transfer, $\alpha_{c a}$, includes a convection part, $\alpha_{\text {con }}$, and a radiation part, $\alpha_{\text {rad }}$, which performs as

$$
\begin{aligned}
& \alpha_{c a}=\alpha_{\mathrm{con}}+\alpha_{\mathrm{rad}} \\
& \alpha_{\mathrm{rad}}=0.23 \times 10^{-6} \varepsilon\left(\frac{T_{\mathrm{wall}}+T_{e n}}{2}\right)^{3},
\end{aligned}
$$

where the emission ratio, $\varepsilon$, is obtained as 0.05 .

The convection part can be divided into two parts, free and forced convection. According to the investigations by Funck (1985) and employed in British Standards Institute (2001), the following expressions can be presented that accommodates exposed case surface area against that exposed to forced cooling:

$$
\alpha_{\text {con }}=\alpha_{\text {free }}\left(1-\frac{A_{\text {air }}}{A_{c a}}\right)+\alpha_{\text {forced }} \frac{A_{\text {air }}}{A_{c a}} \eta^{*},
$$

where

$$
\eta^{*}=\frac{T_{\mathrm{wall}}-T_{\mathrm{air}}}{T_{\mathrm{wall}}-T_{e n}} .
$$

As this DCT case without thermal finning, the free and forced convection can be followed as:

For free convection $\left(V_{\text {air }} \leq 1.5 \mathrm{~m} / \mathrm{s}\right)$ :

$$
\alpha_{\text {free }}=18 h_{c a}^{-0.1}\left(\frac{T_{\text {wall }}-T_{e n}}{T_{e n}}\right)^{0.3} .
$$

For forced convection $\left(V_{\text {air }}>1.5 \mathrm{~m} / \mathrm{s}\right)$ :

$$
\alpha_{\text {forced }}=\frac{0.0086\left(R_{e}^{*}\right)^{0.64}}{l_{x}},
$$

where

$$
\begin{aligned}
& R_{e}^{*}=\sqrt{R_{e}^{2}+\frac{G_{r}}{2.5}} \\
& R_{e}=\frac{v_{\text {air }} l_{x}}{V_{\text {air }}} \\
& G_{r}=\frac{g h_{c a}^{3}\left(T_{\text {wall }}-T_{e n}\right)}{T_{e n} v_{\text {air }}^{2}} .
\end{aligned}
$$




\subsection{DCT temperature change model}

In this section a compact model of the lubricant and transmission case developed utilising simplified lumped inertias. This is chosen over a more detailed geometric heat transfer model, particularly for the transmission case, as the complex geometry of the case with a large number of flanges and bosses does not lend well to simplified geometric representation. This is similar to the modelling strategy provided in Cao et al. (2004), where a thermal model is used as part of a wider investigation of friction estimation in clutches. This method allows for a computationally efficiency analysis of the temperature change, but can and will exclude the benefits of a more complex analysis. Particularly, the identification of any localised heating phenomena that may be identified through other more complex heat transfer methods. For example, Konstantinidis et al. (1997) studies the transient behaviour of exhaust systems using dynamic thermal models with and without the use of flanges and demonstrates a minor but noticeable difference in simulated results.

In the DCT, all of the power losses $P_{L}$ caused by friction and viscous shear will be changed into heat. From equation (1), the overall quantity of DCT heat $Q_{\text {all }}$ can be obtained as:

$$
Q_{\text {all }}=\int P_{L} \mathrm{~d} t .
$$

The generated heat is partially absorbed by oil $Q_{\text {oil }}$ and DCT structure $Q_{\mathrm{DCT}}$, and partially dissipated by the transmission case $Q_{\text {case }}$,

$$
Q_{\mathrm{all}}=Q_{\mathrm{Ca}}+Q_{\mathrm{oil}}+Q_{\mathrm{DCT}} \text {. }
$$

The heat absorbed by the lubricant oil and the DCT can be obtained using specific heat equation, respectively.

$$
\begin{aligned}
& Q_{\text {oil }}=c_{\text {oil }} m_{\text {oil }} \Delta T \\
& Q_{\mathrm{DCT}}=c_{\mathrm{DCT}} m_{\mathrm{DCT}} \Delta T \\
& Q_{\text {all }}=Q_{C a}+c_{\text {oil }} m_{\text {oil }} \Delta T+c_{\mathrm{DCT}} m_{\mathrm{DCT}} \Delta T,
\end{aligned}
$$

where $c_{\mathrm{oil}}$ and $c_{\mathrm{DCT}}$ are the specific heat of the oil and average transmission respectively, and the $m_{\mathrm{oil}}$ and $m_{\mathrm{DCT}}$ are the mass of oil and DCT. $\Delta T$ is the increased temperature caused by absorbing heat.

Combining equations (31)-(34), the increased temperature can be achieved; therefore the rise of the temperature can be expressed as:

$$
T_{\text {oil }}=T_{0}+\Delta T \text {. }
$$

\section{Experimental apparatus}

In this section, test facility and hardware, test instrumentation, data acquisition, and test operation will be briefly presented. 


\subsection{Test facility and hardware}

The test facilities used for this study are shown from Figures 3-5 with several changes to the original UTS powertrain system test rig. The new test rig is based on an electric vehicle power train system, with a $330 \mathrm{~V} \mathrm{DC}$ drive permanent magnet motor which is powered from AC high voltage electric power. The motor drives the wheels through the modified two-speed DCT, and the transmission parameters are shown in Table 1. A group of flywheels and tyres are used to simulate the vehicle inertia. The dynamometer, HPA engine stand 203, as shown in Figure 3, is used to apply load on the flywheels. This part of the test rig consists of two wheels which make contact with flywheels, and another final drive which is connected to the shaft before the dynamometer. The DCT has a separate supply pump. The lubricate fluid will be instead with DCTF rather ATF is shown in Table 2. And the vehicle control unit (VCU) and transmission control unit (TCU) are developed using the dSPACE Micro-Auto Box, as shown in Figure 5.

Figure 3 Modified test rig of two-speed DCT powertrain: (a) laboratory layout and (b) schematic (see online version for colours)

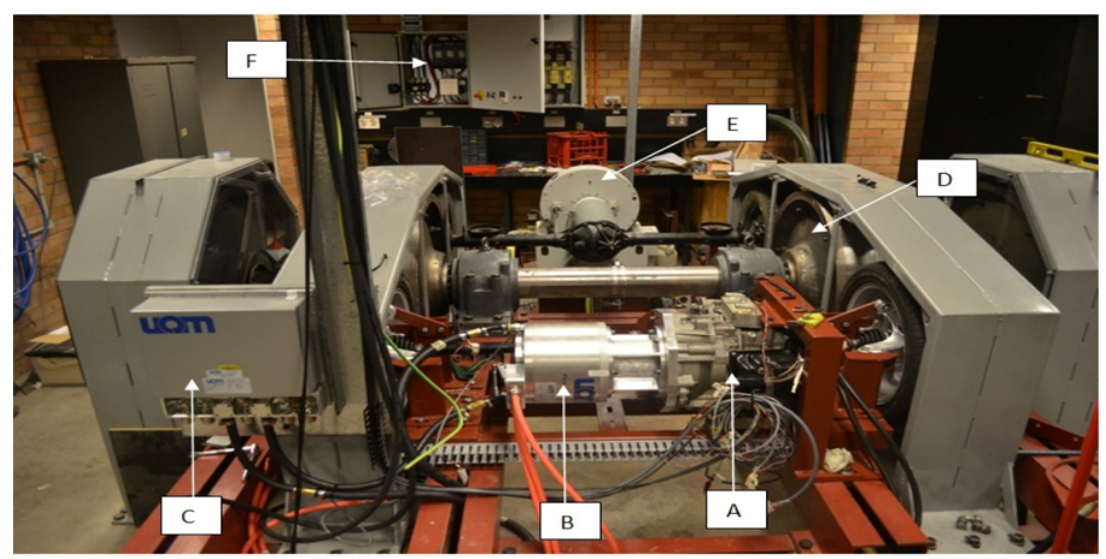

(a)

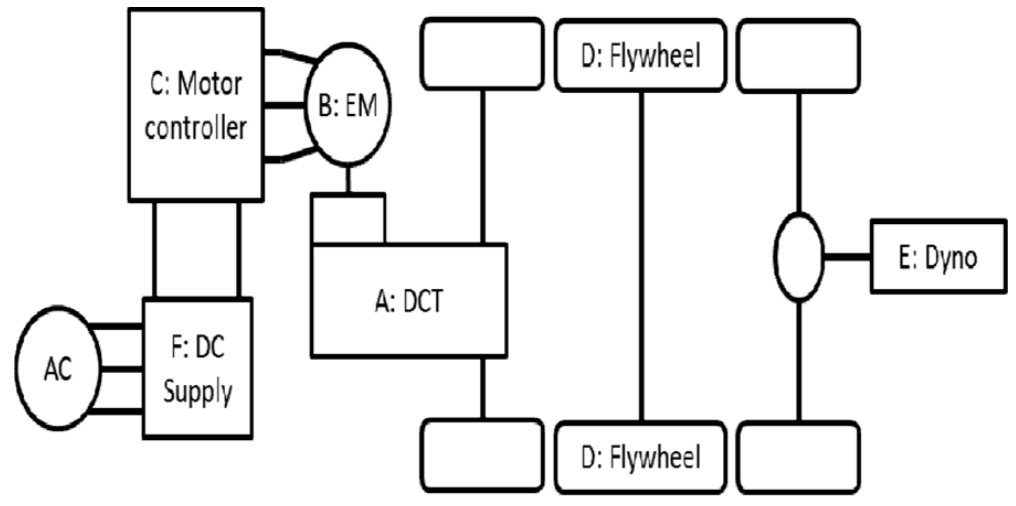

(b)

(A) DCT; (B) electric motor; (C) motor controller; (D) groups of flywheels;

(E) dynamometer and (F) High voltage power supply 
Figure 4 Dual clutch transmission, original one (a), (b), and modified one (c) (see online version for colours)

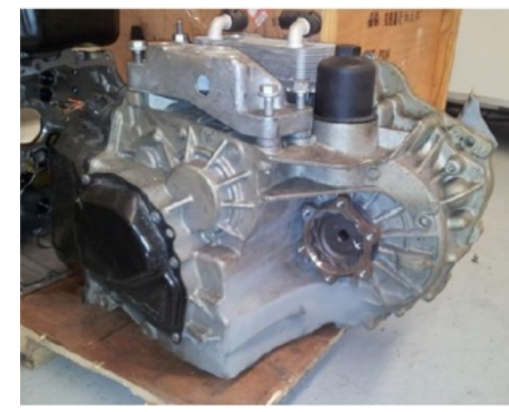

(a)

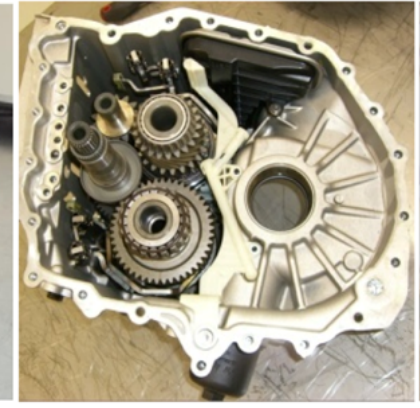

(b)

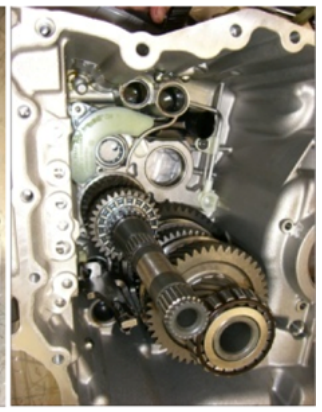

(c)

Figure 5 Schematic UTS EV powertrain system test rig and test procedure (see online version for colours)

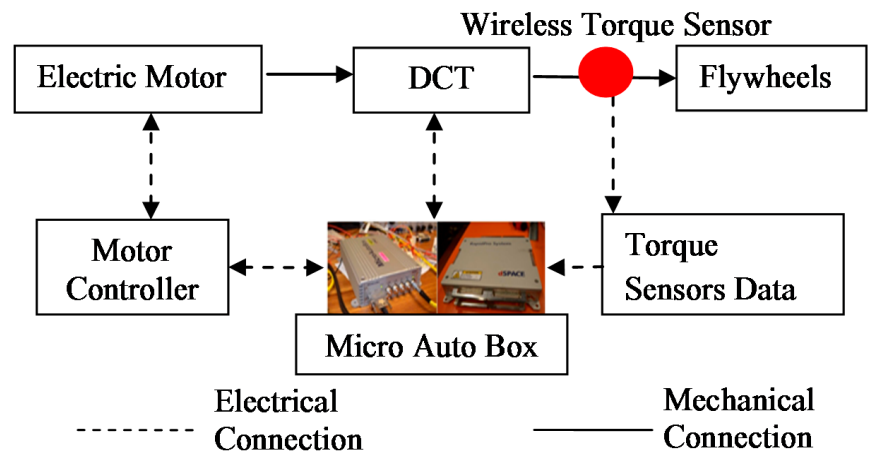

Table 1 DCT clutch plates geometric parameters

\begin{tabular}{|c|c|c|c|c|c|}
\hline \multicolumn{2}{|c|}{ Clutch 1 plates } & \multicolumn{2}{|c|}{ Clutch 2 plates } & \multirow{2}{*}{$\begin{array}{l}\text { Clutch } \\
\text { clearance }\end{array}$} & \multirow{2}{*}{$\begin{array}{l}\text { Plates number } \\
\text { per clutch }\end{array}$} \\
\hline Inner radius & Outer radius & Inner radius & Outer radius & & \\
\hline $57.5 \mathrm{~mm}$ & $69.5 \mathrm{~mm}$ & $81.5 \mathrm{~mm}$ & $96.5 \mathrm{~mm}$ & $0.5 \mathrm{~mm}$ & 8 \\
\hline
\end{tabular}

Table 2 Dual clutch transmission fluid (DCTF) properties and test conditions

\begin{tabular}{lccc}
\hline Flow rate $\left(\mathrm{m}^{3} / \mathrm{s}\right)$ & Oil density $\left(\mathrm{kg} / \mathrm{m}^{3}\right)$ & Oil viscosity $\left(\mathrm{Ns} / \mathrm{m}^{2}\right)$ & Temperature $\left({ }^{\circ} \mathrm{C}\right)$ \\
\hline 0.00005 & 853.4 & 0.0290 & 40 \\
0.00005 & 835 & 0.0167 & 60 \\
0.00005 & 820 & 0.0082 & 80 \\
0.00005 & 810 & 0.0045 & 100 \\
\hline
\end{tabular}

\subsection{Instrumentation and data acquisition}

The test instrumentation used in this study only requires measurement of the input and output speed and torque of the DCT respectively, and the DCT inside oil case 
temperature. Two wireless torque sensors shown in Figure 5 are installed in the front half drive shafts, which are used to collect the output torque data of the DCT. The torque sensors are calibrated before testing and the DCT input torque is equal to the output torque of the electric motor, which can be collected by the motor feedback torque. This data was collected at 1000 samples per second throughout the test via the dSPACE control desk recorder, and then processed in a computer.

\subsection{Test operation}

In order to also reach the two-speed DCT maximum speed design requirements, during the temperature durability test, the vehicle speed should be able to reach over $70 \mathrm{~km} / \mathrm{h}$ when running in 1 st gear. And for the second speed, the vehicle speed should be more than $120 \mathrm{~km} / \mathrm{h}$. The final temperature results should be obtained from stable status, that is, the temperature will not continue to increase while the vehicle continues to run.

The procedures for the test can be described as:

- Check and monitor the primary temperature of the lubricative, environment.

- Apply load and set the expected top-speed. All the data are recorded during the process.

- After the temperature is stable, keep it run for another half hour.

\section{Results and analysis}

After implementing the developed drag torque and thermal behaviour model via simulation, and conducting the experimental test, results from the test and simulations will be presented and analysed in this section.

In order to investigate the effectiveness of the proposed thermal behaviour model, experimental tests are made on the UTS electric vehicle powertrain system test rig. For these tests, the motor speed is ramped up to the target speed using a constant throttle, and the throttle setting is then adjusted to maintain constant motor speed as the lubricant heats up and drag torque losses decrease.

Figure 6(a) and (b) present the experimental and simulation test results from the vehicle running in 1st gear and 2nd gear, with the overall gear ratio in 8.45 and 5.36, respectively. When the speed of the vehicle is over $70 \mathrm{~km} / \mathrm{h}$ or $120 \mathrm{~km} / \mathrm{h}$, the corresponding DCT input speed from the output speed of electric motor is higher than $5000 \mathrm{rpm}$ and $5500 \mathrm{rpm}$, respectively. In order to maintain the constant vehicle speed during running with the expected maximum speed, input torque of DCT is set as $23 \mathrm{Nm}$ and $40 \mathrm{Nm}$, respectively, by operating the electric motor controller. From Figure 6(a) and (b), it can be seen that the simulation results agree reasonably well with corresponding experimental test results. The temperature of DCT rises with the increasing speed, first dramatically increasing, but gradually increasing as the lubricant temperature reaches steady state conditions. After two hours, both of the DCT's temperatures achieve steady state and stop increasing. The final stable temperature for first gear is $71.8^{\circ} \mathrm{C}$, and $2 \mathrm{nd}$ gear in $104.5^{\circ} \mathrm{C}$. And the DCT input speeds are $5276 \mathrm{rpm}$ and $5690 \mathrm{rpm}$, respectively, and corresponding vehicle speeds are $73.5 \mathrm{~km} / \mathrm{h}$ and $125 \mathrm{~km} / \mathrm{h}$ respectively. From these 
two groups of test, the stable temperature with certain input torque can be obtained, as well as the power losses, which will be shown in Figure 7.

Figure 6 Test and simulation results for thermal rise: (a) 1st gear and (b) 2nd gear (see online version for colours)

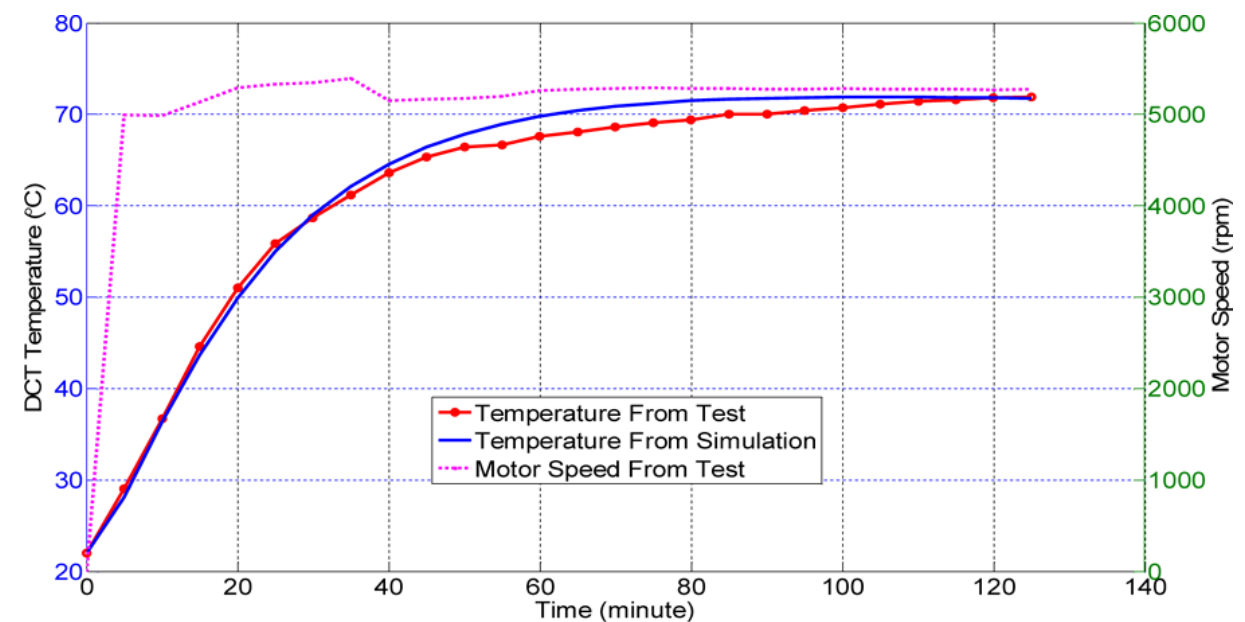

(a)

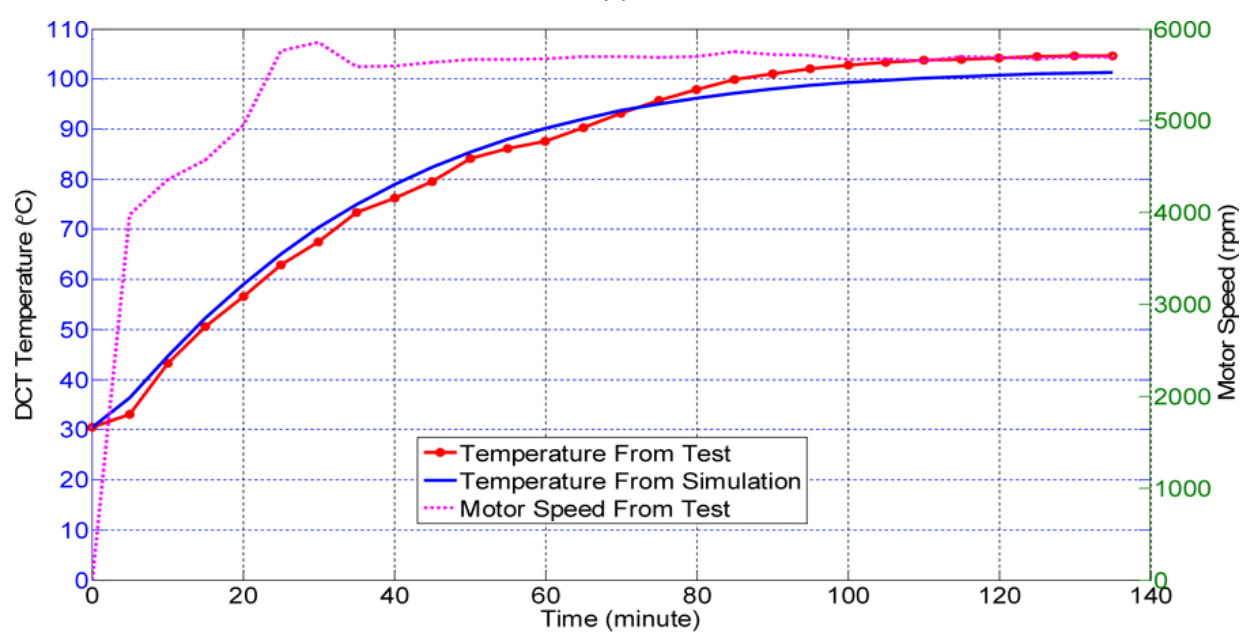

(b)

Figure 7 shows the simulation results by implementing the DCT thermal behaviour model. It presents the relationship of corresponding power losses leading to the DCT temperature in steady state rise from $50^{\circ} \mathrm{C}$ to $125^{\circ} \mathrm{C}$. It indicates that the DCT steady state temperature increases linearly with the increased power losses. Additionally, experimental test results of DCT in two gears are also shown in Figure 7. The errors, less than $5^{\circ} \mathrm{C}$, between the thermal prediction simulation results and the experimental test results, are within the predicted accuracy, around $10^{\circ} \mathrm{C}$, shown in the British Standard (British Standards Institute, 2001). Therefore, the difference between the test results and thermal behaviour model is acceptable and the effectiveness of the thermal behaviour model is demonstrated by the experimental test. 
Figure 7 Relationship between power losses and predicted stable temperature for DCT, and test results (see online version for colours)

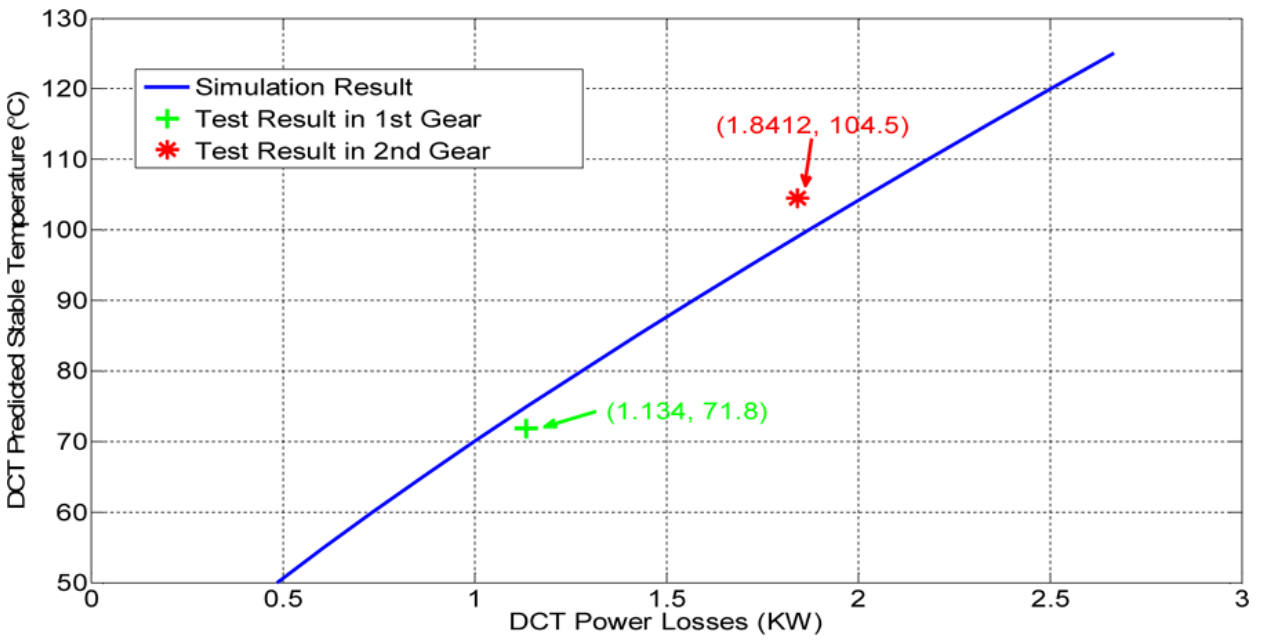

Simulation results from implementing drag torque model are shown in Figure 8. The blue dash line shows the relationship of DCT overall power losses increasing with input speed rising when the vehicle runs in 1st gear, and the red solid line presents the results when the vehicle runs in the 2 nd gear. The power losses obtained from drag torque simulation results and experimental test are nearly equal, so the estimated temperature and power losses by the thermal model able to accurately predict steady state temperature achieved. Moreover, when the input speed is low, less than $2500 \mathrm{rpm}$, the differences of power losses between two gears are minor. While in high speed, over $4000 \mathrm{rpm}$, the differences are becoming large with increasing speed. And at high speed, the DCT power losses in 2nd gear is larger than that in 1st gear, which demonstrates why the final steady temperature in 2nd gear is higher than that of in 1st gear shown in Figure 6. The discontinuity for both gears between 2000 RPM and 3000 RPM is a direct result from the lubricant failing to completely immerse wet clutches at higher speed. This is further discussed in Zhou et al. (2014).

Through the means of combining Figures 7 and 8, different stable temperatures can be estimated at different motor speeds, such as $2000 \mathrm{rpm}, 3000 \mathrm{rpm}$, etc. Simulation results for DCT thermal rise characteristics are shown in Figure 9 with different input speed as well. The environment temperature of both gears is set at $25^{\circ} \mathrm{C}$. It can be seen that the higher the input speed, the acceleration of thermal rise is higher. And the final stable temperature is influenced by the speed.

Thermal rise behaviour at different environment temperatures from $0^{\circ} \mathrm{C}$ to $40^{\circ} \mathrm{C}$ is simulated, with simulation results shown in Figure 10. The solid lines are for 1st gear, and dotted lines are for 2nd gear. From Figure 10, it can be summarised that the final stable temperature of DCT is directly influenced by the environment temperature. This is an important consideration for the use of such transmissions in different operating environments. In particular, there will be increased drag load on the transmission in cooler. 
Figure 8 Simulation results from drag torque model, 1st gear with input torque $23 \mathrm{Nm}$, and 2nd gear with input torque 40 N.m (see online version for colours)

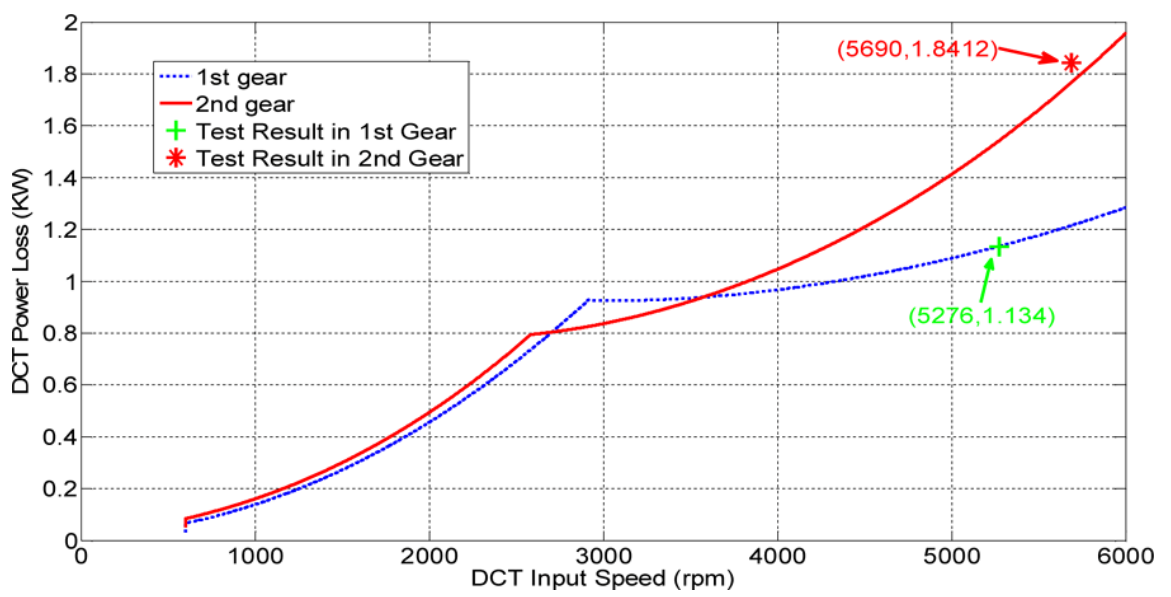

Figure 9 DCT thermal rise at different input speed: (a) 1st gear and (b) 2nd gear (see online version for colours)

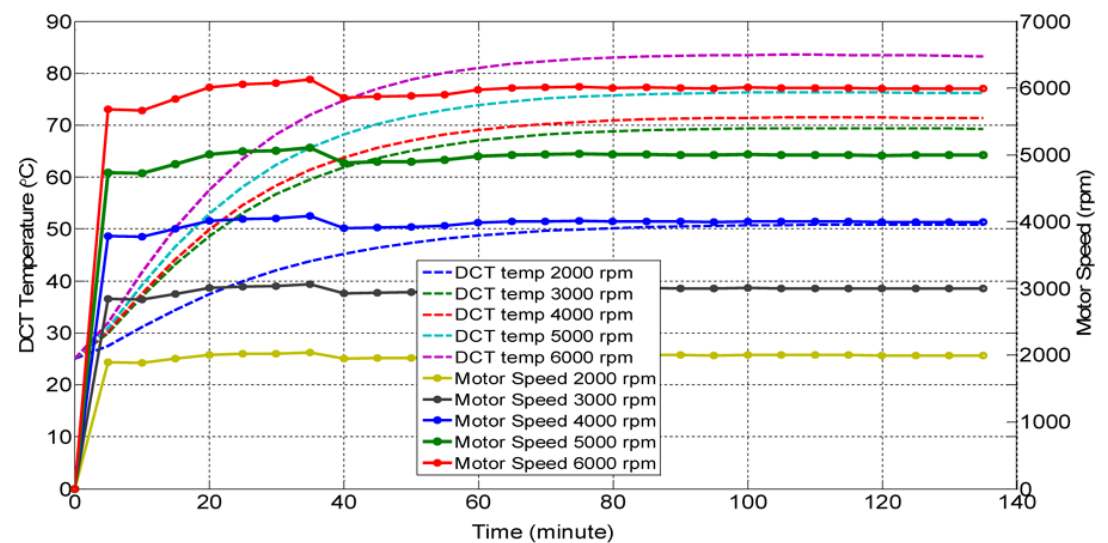

(a)

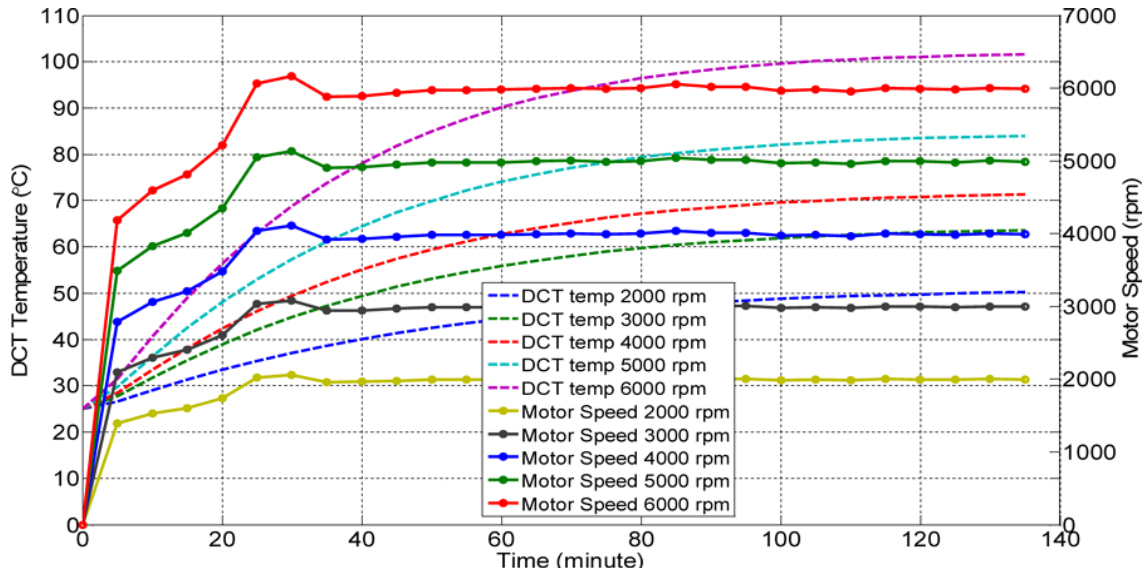

(b) 
Figure 10 Simulations on DCT thermal rise behaviours at different environment temperatures (see online version for colours)

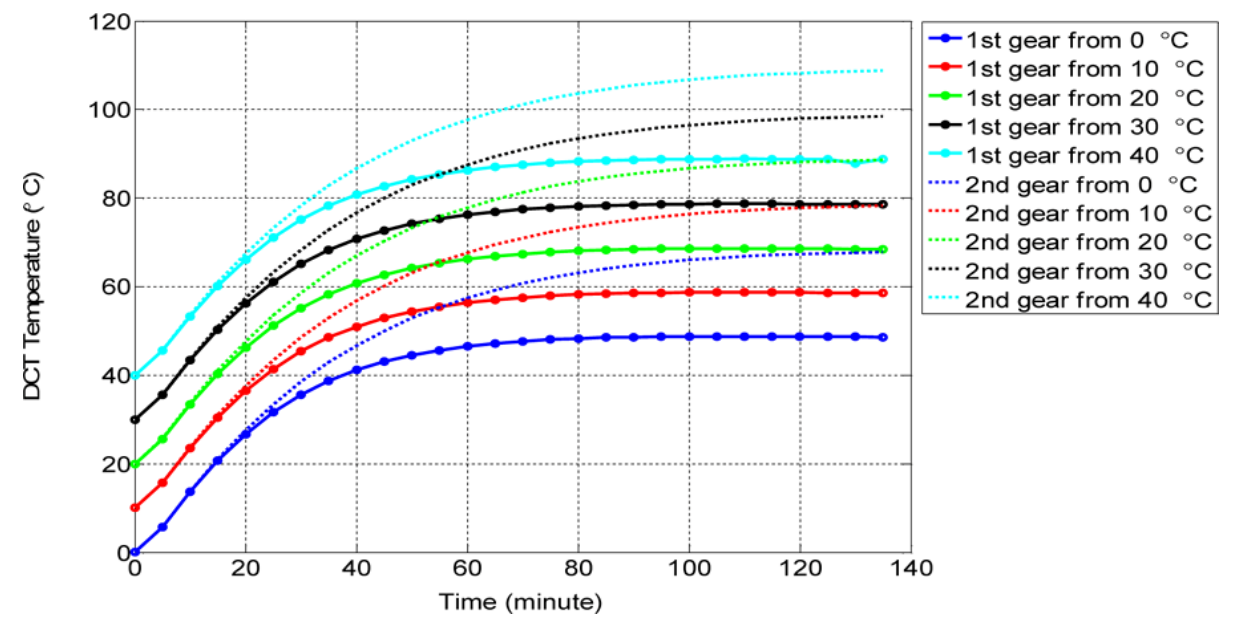

Figure 11 shows the simulation results on power losses from implemented drag torque model with constant input torques. Here, constant input torque $50 \mathrm{Nm}$ for the DCT is set for both first and second gear. From Figure 10, it can be concluded that in low speed, i.e., less than $2600 \mathrm{rpm}$, the power losses in two gears are similar, while above $4000 \mathrm{rpm}$ these losses are different. Furthermore, when the DCT input speed changes from $600 \mathrm{rpm}$ to $6000 \mathrm{rpm}$, the DCT power loss increases by over $1.2 \mathrm{~kW}$ in each case.

Figure 11 Relationship between input speed and power losses (1st and 2nd gear, $50 \mathrm{Nm}$ ) (see online version for colours)

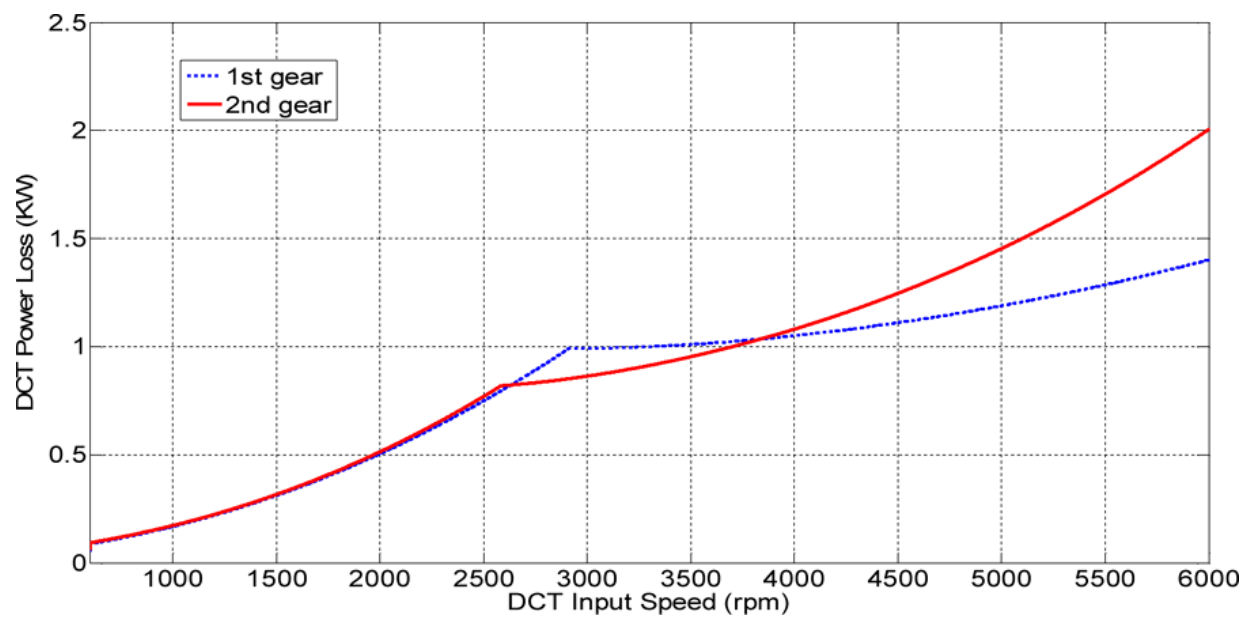

With constant input speed of $3500 \mathrm{rpm}$ and different input torque, the simulation results on DCT power loss are shown in Figure 12. It shows that the power loss in first gear is higher than in second gear by approximate $0.07 \mathrm{~kW}$. Both lines are parallel with each other indicating that the power losses increase linearly with the input torque rising. 
Besides, when the DCT input torque changes from $20 \mathrm{Nm}$ to $80 \mathrm{Nm}$, the DCT power loss changes no more than $0.15 \mathrm{~kW}$ in either line.

Figure 12 Relationship between input torque and power losses (1st and 2nd gear, $3500 \mathrm{rpm}$ ) (see online version for colours)

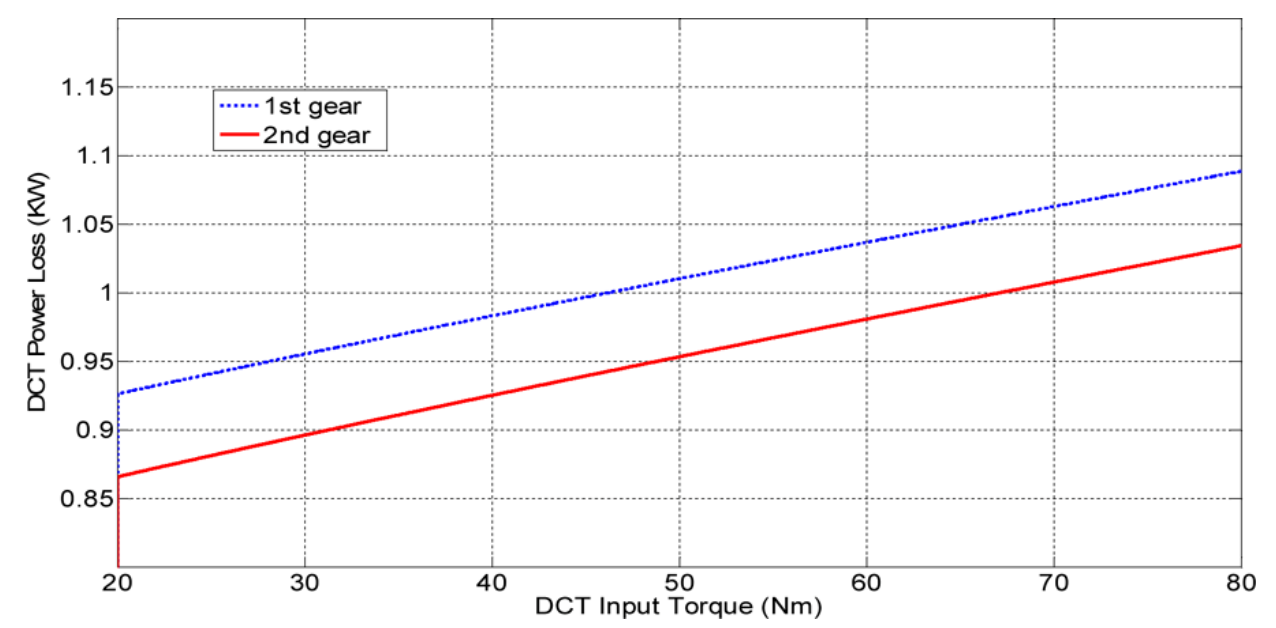

Via comparing Figures 11 and 12, it can be summarised that the impact of speed on DCT power loss is larger than that of torque, i.e., load. As all of the power losses will be converted into heat, and dissipated, it can also be concluded that the impact of speed on the thermal behaviour is higher than that by the load.

\section{Conclusions}

The purpose of this paper is to develop a mathematical model of the thermal behaviour of a prototype DCT. This is achieved through the integration of mathematical models of gear, bearing and clutch losses for the transmission. These losses are defined as the sources of energy generation to heat the lubricating oil. A thermal model of the lubricant and transmission case was also developed to evaluate transmission heat rejection, thus achieving a balanced heating/cooling model of the transmission. Experimental investigation of the transmission thermal behaviour is conducted to validate the effectiveness of the combined drag torque and thermal prediction models, with accurate steady state results achieved. The development of such models can enable the rapid analysis of thermal effects in the DCT case to help improve reliability in initial design and accelerate product development at reduced costs.

Results from simulation and testing of transmission drag torque and thermal behaviour resulted in the attainment of the following conclusions:

- This work reveals that the level of load applied to the transmission has a minor effect in comparison to the speed dependent operation.

- With only a limited number of gear changes required by the transmission, heat rejection through the casing only is sufficient. 
- The impact of gear churning and windage losses become more and more significant with the increasing speed.

- Wet clutch drag loss is the most significant part of the DCT power losses. When designing the two-speed DCT, it is necessary to pay special attention to the thermal reliability to the clutch pack and the hydraulic actuators to avoid overheating.

- The final stable temperature of DCT is significantly influenced by the environment temperature.

Future research includes a more extensive comparison of power losses under a wider range of speeds and load, expanding its application to transient heating models for driving cycle simulations, and applying this thermal behaviour model into powertrain system optimisation. The limitation of this study is that it only considers the steady state status of the thermal behaviours without considering the transient performance of the power losses and the thermal behaviour during shifting.

\section{Acknowledgements}

The support from Beijing Electric Vehicle Co. Ltd., NTC Powertrain, and the Ministry of Science and Technology of the People's Republic of China (2011DFB70060) is gratefully acknowledged. The first author would also like to express his gratitude to China Scholarship Council (2010613031) and the University of Technology Sydney (UTS) (436E2245) for their scholarship support.

\section{References}

British Standards Institute (2001) Gears-Thermal Capacity-Part 1: Rating Gear Drives with Thermal Equilibrium at $95^{\circ} \mathrm{C}$ Sump Temperature. Part 2: Thermal Load-Carrying Capacity, British Standards Institute BS ISO/TR 14179-1:2001.

Cao, M., Wang, K.W., Fujii, Y. and Tobler, W.E. (2004) 'Advanced hybrid neural network automotive friction component model for powertrain system dynamic analysis. part 1: model development', Proceedings of the Institution of Mechanical Engineers, Part D: Journal of Automobile Engineering, Vol. 218, No. 8, pp.831-843.

Chan, C.C., Bouscayrol, A. and Chen, K. (2010) 'Electric, hybrid and fuel-cell vehicles: architectures and modeling', IEEE Transactions on Vehicular Technology, Vol. 59, No. 2, pp.589-598.

Changenet, C. and Velex, P. (2007) 'A model for the prediction of churning losses in geared transmissions - preliminary results', Journal of Mechanical Design, Vol. 129, No. 1, p.128, doi: $10.1115 / 1.2403727$.

Changenet, C., Denis, M. and Nast, D. (1996) 'Thermal study of railway reduction gears', VDI BERICHTE, Vol. 1230, pp.461-471.

Changenet, C., Oviedo-Marlot, X. and Velex, P. (2005) 'Power loss predictions in geared transmissions using thermal networks-applications to a six-speed manual gearbox', Journal of Mechanical Design, ASME, Vol. 128, No. 3, pp.618-625, Available at: http://dx.doi.org/ 10.1115/1.2181601. 
Chen, Z.Y., Li, X.J. and Jiao, B. (2013) 'Design and control strategy of a 4WD hybrid electric vehicle with a two-Speed transmission', Applied Mechanics and Materials, Vols. 380-384, pp.605-608.

Chiara, F. and Canova, M. (2013) 'A review of energy consumption, management and recovery in automotive systems, with considerations of future trends', Proceedings of the Institution of Mechanical Engineers, Part D: Journal of Automobile Engineering, Vol. 227, No. 6, pp.914-936.

Coe, H.H. (1989) Comparison of Predicted and Measured Temperature of UH-60 Helicopter Transmission, NASA Technical Paper No. 2911 1989, p.12.

Dawson, P.H. (2006) 'Windage loss in larger high-speed gears', ARCHIVE: Proceedings of the Institution of Mechanical Engineers, Part A: Power and Process Engineering 1983-1988 (Vols 197-202), Vol. 198, No. 1, pp.51-59.

Diab, Y. (2004) 'Experimental and numerical investigations on the air pumping phenomenon in high speed spur and helical gears', Proceedings of the Institution of Mechanical Engineers, Part C: Journal of Mechanical Engineering Science, Vol. 129, pp.128-133.

Diab, Y., Ville, F. and Velex, P. (2006) 'Investigations on power losses in high-speed gears', Proceedings of the Institution of Mechanical Engineers, Part J: Journal of Engineering Tribology, Vol. 220, No. 3, pp.191-198.

Eastwick, C.N. and Johnson, G. (2008) 'Gear windage: a review', Journal of Mechanical Design. ASME, Vol. 130, No. 3, pp.34001-34006, Available at: http://dx.doi.org/10.1115/1.2829983

Funck, G. (1985) Wärmeabführung Bei Getrieben Unter Quasistationären Betriebsbedingungen.

Goetz, M., Levesley, M.C. and Crolla, D.A. (2004) Integrated Powertrain Control of Gearshifts on Twin Clutch Transmissions, SAE International, Detroit USA, doi: 10.4271/2004-01-1637.

Handschuh, R.F. and Kilmain, C.J. (2002) 'Preliminary investigation of the thermal behavior of high speed-helical gear trains', International Conference on Gears Sponsored by IFTMM: NASA TM-211336, Munich, Germany, pp.867-879.

Harris, T. (1966) Rolling Bearing Analysis, 1st ed., CRC Press.

Hashimoto, H., Wada, S. and Murayama, Y. (1984) 'The performance of a turbulent lubricated sliding bearing subject to centrifugal effect', Trans. Jpn. Soc. Mech. Eng., Ser, C, Vol. 49, No. 446, pp.1753-1761.

Heingartner, P. and Mba, D. (2003) 'Determining power losses in the helical gear mesh', ASME 2003 International Design Engineering Technical Conferences and Computers and Information in Engineering Conference, 2-6 September, 2003, Chicago, Illinois, USA, pp.965-940.

Holmberg, K., Andersson, P. and Erdemir, A. (2012) 'Global energy consumption due to friction in passenger cars', Tribology International, Vol. 47, pp.221-234.

Iqbal, S., Janssens, T. and Desmet, W. (2011) 'Transmitted power and energy flow behavior of degrading wet friction clutches', International Conference on Energy, Water and Environment (ICEWE 2011) (ICEWE), pp.34-40, http://scholar.google.com/scholar?hl=en\&btnG=Search \&q=intitle:Transmitted + power + and + energy + flow + behavior + of + degrading + wet + friction + clutches $\# 0$

Iritani, M., Aoki, H., Suzuki, K. and Morita, Y. (1999) Prediction Technique for the Lubricating Oil Temperature in Manual Transaxle, SAE International, Detroit USA.

Joule, D., Hinduja, S. and Ashton, J.N. (1988) 'Thermal analysis of a spur gearbox part 1: steady state finite element analysis', Proceedings of the Institution of Mechanical Engineers, Part C: Journal of Mechanical Engineering Science, Vol. 202, No. 4, pp.245-256.

Kato, Y.T. and Murasugi, H.H. (1993) 'Fuel economy improvement through tribological analysis of the wet clutches and brakes of an automatic transmission', Society of Automotive Engineers of Japan, Vol. 16, No. 12, pp.57-60. 
Konstantinidis, P.A., Koltsakis, G.C. and Stamatelos, A.M. (1997) 'Transient heat transfer modelling in automotive exhaust systems', Proceedings of the Institution of Mechanical Engineers, Part C: Journal of Mechanical Engineering Science, Vol. 211, No. 1, pp.1-15.

Li, S., Vaidyanathan, A., Harianto, J. and Kahraman, A. (2009) 'Influence of design parameters on mechanical power losses of helical gear pairs', Journal of Advanced Mechanical Design, Systems and Manufacturing, Vol. 3, No. 2, pp.146-158.

Marklund, P., Mäki, R., Larsson, R., Höglund, E., Khonsari, M.M. and Jang, J. (2007) 'Thermal influence on torque transfer of wet clutches in limited slip differential applications', Tribology International, Vol. 40, No. 5, pp.876-884.

Merwerth, J. (2014) The Hybrid-Synchronous Machine of The New BMW i3 and i8.

Michlin, Y. and Myunster, V. (2002) 'Determination of power losses in gear transmissions with rolling and sliding friction incorporated', Mechanism and Machine Theory, Vol. 37, No. 2, pp.167-174.

Naunheimer, H., Bertsche, B., Ryborz, J. and Novak, W. (2011) Automotive Transmissions Fundamentals, Selection, Design and Application, 2nd ed., Springer, Berlin Heidelberg, doi: 10.1007/978-3-642-16214-5.

Patel, P.D. and Patel, J.M. (2012) 'An experimental investigation of power losses in manual transmission gear box', International Journal of Applied Research in Mechanical Engineering, Vol. 2, pp.1-5.

Phillips, A.E. and Association, A.G.M. (1996) The Development of a Practical Thermal Rating Method for Enclosed Gear Drives. American Gear Manufacturers Association (Technical Papers). Available at: https://books.google.com.au/books?id=ihCgAAAACAAJ

Rosander, P., Bednarek, G., Seetharaman, S. and Kahraman, A. (2008) 'Development of an efficiency model for manual transmissions', ATZ Worldwide, Vol. 110, No. 4, pp.36-43.

Roser, H., Walker, P.D. and Zhang, N. (2013) 'Robustness analysis of two-speed electric vehicles', Proceedings of the ASME 2013 International Mechanical Engineering Congress and Exposition, San Diego, USA, pp.1-7.

Seetharaman, S. (2008) 'A model to predict mechanical power losses of manual transmissions', Automobiltechnische Zeitschrift, Vol. 4, pp.346-357.

Walker, P.D., Abdul Rahman, S., Zhu, B. and Zhang, N. (2013) 'Modelling, simulations and optimisation of electric vehicles for analysis of transmission ratio selection', Advances in Mechanical Engineering, doi: 10.1155/2013/340435.

Walker, P.D., Zhang, N., Tamba, R. and Fitzgerald, S. (2011) 'Simulations of drag torque affecting synchronisers in a dual clutch transmission', Japan Journal of Industrial and Applied Mathematics, Vol. 28, No. 1, pp.119-140.

$\mathrm{Xu}$, H., Kahraman, A., Anderson, N.E. and Maddock, D.G. (2007) 'Prediction of mechanical efficiency of parallel-axis gear pairs', Journal of Mechanical Design, Vol. 129, No. 1, p.58.

Yang, F., Du, L., Yao, C., Du, J. and Yu, P. (2014) The Study of Operating Efficiency Enhancement of Traction Motor with the Application of a Two-speed Transmission in an Electric Bus, SAE International.

Zhou, X., Walker, P., Zhang, N. and Zhu, B. (2013a) Performance Improvement of a Two Speed EV Through Combined Gear Ratio and Shift Schedule Optimization, SAE Technical Paper Series.

Zhou, X., Walker, P., Zhang, N., Zhu, B. and Ruan, J. (2013b) 'Simulation of thermal behavior of a two-speed dual clutch transmission', APCOM and ISCM 2013, Singapore, pp.1-5.

Zhou, X., Walker, P., Zhang, N., Zhu, B. and Ruan, J. (2014) 'Numerical and experimental investigation of drag torque in a two-speed dual clutch transmission', Mechanism and Machine Theory, Elsevier Ltd., Vol. 79, pp.46-63, doi: 10.1016/j.mechmachtheory .2014.04.007. 


\section{Nomenclature}

\begin{tabular}{|c|c|c|}
\hline$A_{c a}$ & Surface area of transmission case $\left(\mathrm{m}^{2}\right)$ & 0.86 \\
\hline$A_{\text {oil }}$ & Oil-side surface area of transmission case $\left(\mathrm{m}^{2}\right)$ & 0.85 \\
\hline$c_{\text {oil }}$ & Specific heat of oil $(\mathrm{J} / \mathrm{kg}, \mathrm{K})$ & 2090 \\
\hline$c_{\mathrm{DCT}}$ & The average specific heat of transmission ( $\mathrm{J} / \mathrm{kg}$, Kelvin) & 880 \\
\hline$h_{c a}$ & Height of gearbox housing $(\mathrm{m})$ & 0.34 \\
\hline$G_{r}$ & Grashoff number & - \\
\hline$K$ & Heat transmission coefficient (W/m $/ \mathrm{m}^{2}$ Kelvin) & - \\
\hline$m_{\mathrm{oil}}$ & Mass of oil (kg) & 5.1 \\
\hline$P_{B}$ & Power losses caused by bearings drag torque $(\mathrm{kW})$ & - \\
\hline$P_{\text {con }}$ & Power losses caused by concentric shaft drag torque $(\mathrm{kW})$ & - \\
\hline$P_{C h}$ & Power losses caused by gear churning $(\mathrm{kW})$ & - \\
\hline$P_{C l}$ & Power losses caused by wet clutch plates drag torque $(\mathrm{kW})$ & - \\
\hline$P_{G}$ & Power losses caused by gear meshing drag torque $(\mathrm{kW})$ & - \\
\hline$P_{L}$ & Total power losses in DCT $(\mathrm{kW})$ & - \\
\hline$Q_{c a}$ & Quantity of heat dissipated by the transmission case $(\mathrm{J})$ & - \\
\hline$Q_{\text {all }}$ & Overall quantity of DCT heat $(\mathrm{J})$ & - \\
\hline$Q_{\text {oil }}$ & Quantity of heat absorbed by oil (J) & - \\
\hline$Q_{\mathrm{DCT}}$ & Quantity of heat absorbed by DCT structure (J) & - \\
\hline$R_{e}$ & Reynold's number & - \\
\hline$T_{\text {oil }}$ & Oil temperature (Kelvin) & - \\
\hline$T_{e n}$ & Environment temperature (Kelvin) & 298 \\
\hline$T_{0}$ & The primary temperature (Kelvin) & - \\
\hline$T_{\text {wall }}$ & Temperature of housing wall (Kelvin) & - \\
\hline$\alpha_{\mathrm{oil}}$ & Oil-side heat transfer coefficient (W/m² Kelvin) & 50 \\
\hline$\alpha_{c a}$ & Air-side heat conduction $\left(\mathrm{W} / \mathrm{m}^{2} \mathrm{~K}\right)$ & 200 \\
\hline$\alpha_{\text {con }}$ & Convection $\operatorname{part}\left(\mathrm{W} / \mathrm{m}^{2} \mathrm{~K}\right)$ & - \\
\hline$\alpha_{\mathrm{rad}}$ & Radiation part $\left(\mathrm{W} / \mathrm{m}^{2} \mathrm{~K}\right)$ & - \\
\hline$\alpha_{\text {free }}$ & Heat transfer coefficient due to free convection $\left(\mathrm{W} / \mathrm{m}^{2}, \mathrm{~K}\right)$ & - \\
\hline$\alpha_{\text {forced }}$ & Heat transfer coefficient due to forced convection $\left(\mathrm{W} / \mathrm{m}^{2}, \mathrm{~K}\right)$ & - \\
\hline$\lambda_{\text {wall }}$ & Coefficient of thermal conduction of housing $(\mathrm{W} / \mathrm{m}, \mathrm{K})$ & 160 \\
\hline$\delta_{\text {wall }}$ & Mean housing wall thickness (m) & 0.012 \\
\hline$\varepsilon$ & Emission ratio & 0.05 \\
\hline$\eta^{*}$ & Temperature ratio & - \\
\hline$v_{\text {air }}$ & Impingement velocity (m/s) & 1 \\
\hline$\Delta T$ & Increased temperature caused by absorbing heat (Kelvin) & - \\
\hline
\end{tabular}

